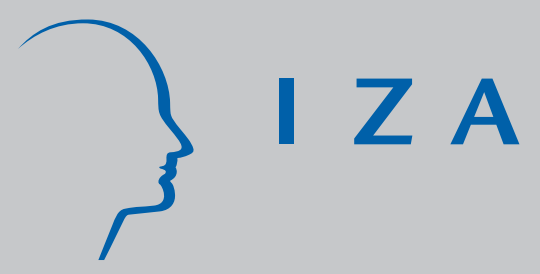

IZA DP No. 3197

Why Develop Open Source Software?

The Role of Non-Pecuniary Benefits, Monetary Rewards and Open Source Licence Type

Robert M. Sauer

December 2007 


\title{
Why Develop Open Source Software? The Role of Non-Pecuniary Benefits, Monetary Rewards and Open Source Licence Type
}

\author{
Robert M. Sauer \\ University of Southampton \\ and IZA
}

\section{Discussion Paper No. 3197 \\ December 2007}

\author{
IZA \\ P.O. Box 7240 \\ 53072 Bonn \\ Germany \\ Phone: +49-228-3894-0 \\ Fax: +49-228-3894-180 \\ E-mail: iza@iza.org
}

\begin{abstract}
Any opinions expressed here are those of the author(s) and not those of the institute. Research disseminated by IZA may include views on policy, but the institute itself takes no institutional policy positions.

The Institute for the Study of Labor (IZA) in Bonn is a local and virtual international research center and a place of communication between science, politics and business. IZA is an independent nonprofit company supported by Deutsche Post World Net. The center is associated with the University of Bonn and offers a stimulating research environment through its research networks, research support, and visitors and doctoral programs. IZA engages in (i) original and internationally competitive research in all fields of labor economics, (ii) development of policy concepts, and (iii) dissemination of research results and concepts to the interested public.
\end{abstract}

IZA Discussion Papers often represent preliminary work and are circulated to encourage discussion. Citation of such a paper should account for its provisional character. A revised version may be available directly from the author. 
IZA Discussion Paper No. 3197

December 2007

\section{ABSTRACT \\ Why Develop Open Source Software? \\ The Role of Non-Pecuniary Benefits, Monetary Rewards and Open Source Licence Type}

A review of the basic theory of optimal open-source software contributions points to three key factors affecting supply: non-pecuniary benefits, future expected monetary returns, and opensource licence type. This paper argues that existing large-scale software developer surveys are inadequate for measuring the relative importance of these three factors. Moreover, previous econometric studies that collect their own unique datasets generally measure the importance of only one supply factor in isolation. To fill the gap, I specify a dynamic programming model of joint labour supply and open-source contribution decisions that can provide empirical estimates of relative importance within a single unified framework.

JEL Classification: $\quad$ C61, C80, J24, J44

Keywords: $\quad$ software, open-source, labour supply, dynamic programming

Corresponding author:

Robert M. Sauer

University of Southampton

School of Social Sciences

Southampton SO17 1BJ

United Kingdom

E-mail: R.M.Sauer@soton.ac.uk

\footnotetext{
* I thank Julian Morris, Eric Raymond, Corinne Sauer and Margaret Stevens for providing insightful comments on previous drafts.
} 


\section{Introduction}

Over the past decade, there has been a phenomenal increase in the adoption of open source software by both firms and governments. In 1996, the market share of the open source operating system Linux, in the global server market, was roughly 6 percent. By the year 2003, Linux's market share had reached 28 percent. Between 1996 and 2003, Linux overtook its proprietary software competitors Unix and Netware and substantially closed the gap with the traditional leader in the sector, Microsoft Windows (see Wheeler (2004)).

The reasons why firms and governments have increased their adoption of open source software are generally well-understood. In certain computing environments, the total cost of ownership (TCO) of open source software can be lower than the TCO of proprietary software. Open source software is also now considered to be of equivalent or higher quality than many proprietary software alternatives. The increasing demand for open source software is mainly a function of falling TCO and improved program functionality (see MacCormack (2003)). ${ }^{1}$

In stark contrast to the demand side of the software market, the main determinants of the supply of open source software are still unknown. The central puzzle is that most open source software developers are volunteers that supply their labor for free, and many developers agree to have their contributions licensed in such a way that it is difficult for them to directly profit from the resulting software product. Previous research addressing this puzzle has pointed to non-pecuniary benefits, future monetary rewards and open source license type as the three key factors influencing the individual's decision to voluntarily contribute to open source development (see, e.g., Lerner and Tirole (2002)). However, there is currently very little empirical evidence on the relative importance of these three supply factors. Obtaining empirical

\footnotetext{
${ }^{1}$ Governments may also prefer open source software solutions for "non-pecuniary" reasons. For example, open source software can in some cases be more easily adapted to meet linguistic and cultural preferences.
} 
measures of relative influence can be practically important for properly predicting future open source supply levels and assessing the impact of proposed changes in public policy towards open source development.

In this paper, the basic theory of open-source supply contributions is outlined and the relevant econometric evidence is reviewed. It is pointed out that the empirical literature currently falls short because it generally looks at the role of monetary rewards and open-source licence type in isolation. There are also no studies, to the best of my knowledge, that attempt to empirically identify the role of non-pecuniary benefits in the supply decision. In order to fill this gap in the literature, I propose a model of joint labour supply and open-source software contribution decisions that can be used to measure the relative influence of non-pecuniary benefits, future monetary rewards, and open-source licence type in a single model. The dynamic model could be easily empirical implemented were panel data to be collected on the decisions of open-source and proprietary software developers.

The rest of the paper is organized as follows. In the next section, the basic theory of voluntary contributions to the open-source development process is outlined. In Section III, the drawbacks of existing large-scale surveys are highlighted, previous econometric findings from studies that collect their own unique data sets are discussed. In section IV, the forward-looking model of software-developer employment and opensource contribution decisions, incorporating all three supply factors in a single model, is specified. The final section summarizes and concludes. 


\section{The Basic Theory of Voluntary Software Con- tributions}

Consider the case of a software developer that has written a fix for a bug in an existing software program. ${ }^{2}$ Assume that the developer was originally motivated to write the patch for his own personal use of the program. In addition, assume that there is a very high degree of uncertainty regarding the value of the patch to other software developers/consumers so that there is no non-zero price at which others are willing to buy it. Under these conditions, the developer of the patch will be indifferent between keeping the patch for himself, which yields zero profits, and distributing the patch to the public for free, which also yields zero profits (assuming zero costs of distribution). The costs that the developer initially incurs to produce the patch are not relevant in the decision to release or not release because development costs are sunk.

In the above scenario, the software developer's indifference between keeping the patch private, and releasing the patch to the public for free, can be broken by assuming that there are differential expected future returns between the two options. Raymond (1999c) maintains that higher future returns are captured when the patch is released for free because it gives rise to reciprocal giving. That is, distributing the patch to the public for free will encourage other software developers to do the same with their own privately produced patches, and many of these patches will turn out to be useful to others in the community. Hence, releasing the patch for free is the optimal choice for each developer, and is the equilibrium outcome.

Although Raymond relies rather heavily on a social psychological notion of reciprocal giving, this assumption is not at all necessary for breaking the tie between releasing and not releasing. The same equilibrium outcome of voluntary contributions could arise if one's reputation as a skilled programmer is enhanced by distributing the patch for free. That is, by revealing one's programming code, the developer can

\footnotetext{
${ }^{2}$ The following example is adapted from Raymond (1999c).
} 
signal his skill level, or stock of programming human capital, to the community of software developers. This could lead to differentially higher expected future returns through higher future skill prices.

This labor market signaling function of voluntary contributions is the central notion in the work of Lerner and Tirole (2002). Lerner and Tirole (2002) also note that the signaling incentive to voluntary contributions suggests that strategic complementarities may be important. In order to signal one's skills most effectively, an open source developer will mostly likely want to participate in open source projects that also attract many other developers. The marginal benefit of voluntarily contributing increases with the number of developers involved in the project. Along these lines, Johnson (2002) models a developer's decision to invest effort in developing code that will become a public good, and formally illustrates the effect of a changing contributor population size.

Although the central focus in Lerner and Tirole (2002) is on the signaling role of open source participation, and in Raymond (1999c) it is on reciprocal giving, the role of non-pecuniary benefits is also clearly recognized in previous research. For example, in Raymond (1999b) the open source community is conceived of as a gift culture in which a developer's status in that community depends on the quality of the software gift that he/she gives to others. Another important source of non-pecuniary benefits identified by Raymond (1999b) is ego-gratification, or peer recognition. Developers are likened to craftsman who want others to admire their artistic style of coding. Non-pecuniary benefits can also come in the form of ideological satisfaction for those that believe software should be supplied free of charge or that Microsoft abuses its market position. ${ }^{3}$

While it seems plausible that higher non-pecuniary benefits and expected future

\footnotetext{
${ }^{3}$ There are also developers that receive wages from commercial firms for working on open source projects. The reasons why commercial firms might want to pay developers to work on open source projects will be mentioned below.
} 
monetary returns can be captured through choosing to voluntarily contribute, it is somewhat implausible to maintain that there are zero (or negligible) distribution costs to open source participation. In fact, distributing a patch to the public for free could be very costly when there is a heavy "regulatory burden" imposed upon submitters. For example, in some projects developers may be forced to comply with standards that require one to "clean up the patch, write a ChangeLog entry, and sign the FSF assignment papers" (Raymond $(1999 c)$, p. 7). The advantages derived from egogratification and higher future monetary rewards could be outweighed by the current and future costs of submission and distribution.

It is interesting to note in this context that Raymond (1999c) characterizes the Linux project as one with a relatively liberal organizational structure, and hence a relatively low cost of submission. He sees this as an important reason why Linux continues to grow and succeed. In contrast, projects with more centralized structures, like those associated with the Free Software Foundation (FSF), have a higher cost of submission and are generally not growing as fast. Thus, variation in organizational structure and associated costs of distribution may be critical parameters in the open source developer's optimization problem, and in the eventual market share of an open source product.

The voluntary contributions optimization model outlined above not only provides a useful and simple theoretical framework for identifying the main factors that affect supply at the individual level, but it can also be adapted to help explain the decision of commercial firms to voluntarily open-up internally developed code. Following another example in Raymond (1999c), suppose the internally developed software is an intermediate good in the firm's production process, e.g., an accounting package. ${ }^{4}$ As in the individual developer's decision problem, the firm may choose to keep the initially developed code closed, or may release the code into the public domain. The

\footnotetext{
${ }^{4}$ Raymond argues that approximately $95 \%$ of all software development activities are for intermediate goods in the production process, such as accounting packages.
} 
initial development costs are sunk.

The main expected future benefit to releasing the code into the public domain is the receipt of programming input from hundreds of additional developers who can improve program functionality. This has been expressed in Raymond (1999a) as "given enough eye balls, all bugs are shallow." ${ }^{5}$ However, while the firm may hope to benefit from the dispersed knowledge of developers in the wider open source community, there is also a chance that no help will be forthcoming at all. This is because the desire of developers to participate in an open source project initiated by a commercial firm may be weak. With firm-initiated projects, developers are less likely to reap non-pecuniary benefits related to ideological satisfaction and/or enhanced status in the open source community. For example, contributing to improved functionality of an accounting package for a commercial firm is generally considered to be less "challenging" than contributing to a mathematical program to be used by researchers. Developers may also intensely fear that the firm will "hijack" the resulting software product and eventually close it off from further open source development.

It is for these latter reasons that the form of intellectual property protection, or the license under which a project is released, can be a critical factor in the developer's decision to supply labor to open source development. In some cases, it may be that the only way a firm (or other project initiator) can induce developers to participate in an open source project is to put the project under a restrictive license such as the GNU General Public License (GPL). GPL is a restrictive license because it requires that the initial code and all modifications remain freely available, that any derivative work is also licensed as GPL, and that the resulting code not be mixed with closed source software in any re-distributed works. GPL makes commercialization of the

\footnotetext{
${ }^{5}$ Raymond is essentially applying ideas developed in Hayek (1945) to the case of open source software production. That is, open source developers have different "local" knowledge that can be effectively tapped to the firm's benefit through the coordinating institution of open source collaboration.
} 
resulting code difficult. Placing the project under GPL, rather than BSD or some other less restrictive license, can help satisfy ideological preferences, reduce the fear of hijacking, and induce greater participation from the developer community. ${ }^{6}$

From the firm's perspective, opening-up the code, even under a restrictive license such as GPL, can be advantageous for reasons other than improved program functionality. For example, releasing the code can help spread the risk of development. If the code remains closed, or internal to the firm, it could be costly to find suitable replacement programmers after the original in-house developers have left. Releasing the code to the open source community can provide more continuity and fluid program maintenance, acting as a form of insurance against the deleterious effects of turnover in the market for developers (Raymond (1999c)). Firms can also benefit from providing complementary support and consulting services for open source products, from increased operating system standardization which lowers the costs of providing complementary proprietary software and hardware products, and from imbedding open source components in proprietary software and hardware bundles in order to lower licensing fees. As a result of these potential benefits, several large firms have been known to directly fund open source projects and offer salaries to open source developers (see Berlecon Research (2002)).

On the cost side of opening-up internally developed code, the firm may suffer lost profits due to competitors in the industry being able to free-ride and benefit from the program, without having incurred initial development costs. The extent of lost profits will likely depend on the generality of the program and the industry's market structure. For example, if there is a high degree of competition in the industry then the costs of releasing the code may be large (see von Hippel (2002), Harhoff et al. (2003), Henkel (2005) and Maurer and Scotchmer (2005)). On the other hand, as Lerner and Tirole (2005a) point out, if network effects and switching costs are

\footnotetext{
${ }^{6} \mathrm{BSD}$ stands for Berkeley Software Distribution (BSD). The BSD license is more conducive to commercialization of the resulting code.
} 
considerable, then there will be little competition, the second-best software package may have only a tiny market share, and the loss in profits due to releasing the code will be negligible. ${ }^{7}$

\section{Empirical Findings}

Recently, a number of different surveys of open source developers have become available to researchers. Most notable are the FLOSS (Free/Libre and Open Source Software) surveys which tend to over-sample developers from particular geographical regions. In the first subsection, we discuss the limited usefulness of the FLOSS-EU survey for studying the determinants of open source software supply. In the second subsection, we review several econometric studies of the factors that influence a developer's decision to participate in the open source development process.

\subsection{FLOSS-EU}

FLOSS-EU was one of the first developer surveys ever to be conducted. It was administered online between February and April 2002. The questionnaire was initially posted on several open source/free software (OS/FS) websites and was further distributed by developers themselves. The number of respondents in FLOSS-EU is 2,784.

Tables 1 and 2 present a selected set of descriptive statistics from FLOSS-EU calculated by Gosh et al. (2002). Table 1 indicates that the respondents are generally young, male, single, and highly educated. The most common profession is software engineer, followed by programmer, consultant and university employee. A little more than $20 \%$ of the sample consists of university students. ${ }^{8}$ Approximately $70 \%$ of the

\footnotetext{
${ }^{7}$ Firms operating in low transactions costs environment may be able to mitigate free-rider costs of opening-up the code by forming a consortium (see, e.g., West and Gallagher (2004)).

${ }^{8}$ Nearly identical percentages of students are found in the developer surveys analyzed by Hertel et al. (2003) and Lakhani and Wolf (2005).
} 
respondents earn less than 3000 Euro/USD a month, and 70\% work 10 hours or less a week developing OS/FS. Since the survey was distributed via the internet, it reached developers in a number of different countries. For example, $70 \%$ were born in an EU country. Only $10 \%$ of the respondents are working, at the time of the survey, in a country other than the country in which they were born.

More directly relevant to the determinants of open source supply, FLOSS-EU contains a number of questions related to the motivations of OS/FS developers. The top panel of Table 2 displays the percentage of respondents choosing a pre-selected set of reasons for becoming an OS/FS developer. Each respondent was allowed to choose more than one reason in the list so the percentages can add to more than $100 \%$.

The table shows that $79 \%$ of the respondents joined the OS/FS community because they were interested in learning and developing new skills. The next most frequent reason, accounting for $49 \%$ of respondents, was a desire to share already existing knowledge and skills. The desire to improve job opportunities, to get a reputation in the OS/FS community, and to make money are relatively less important, but are not negligible.

The bottom panel of Table 2 displays the distribution of responses to a question on whether the developers receive monetary and non-monetary rewards for development of OS/FS. Respondents were allowed to choose more than one answer. The response frequencies reveal that more than half of the developers earn money from their OS/FS activities. Among those that earn money, a non-negligible number are directly paid for administering or developing OS/FS. A relatively high proportion claims to have secured their job as a result of their OS/FS experience. Table 2 illustrates that monetary benefits to OS/FS participation are common.

The form of the questions and responses in Table 2 make it difficult to fruitfully use these data for generalizing about key motivations. Many developers have a desire to share existing skills, wish to learn new skills (e.g., students), and earn money 
either directly or indirectly from their open source activities. However, it is not obvious how one could map these responses into metrics that would enable a researcher to disentangle the relative importance of non-pecuniary benefits, future monetary rewards and open source license type. A similar interpretational problem arises with the responses to other developer surveys that have recently been conducted (see, e.g., Boston Consulting Group (2003), Haruvy, Wu and Chakravarty (2003), Lakhani and von Hippel (2003) and Lakhani and Wolf (2005)).

It is important to note that current developer surveys have additional drawbacks because they only reach software developers that participate in open source projects. A control group of software developers that does not participate in open source projects is completely absent. Another major problem is that current surveys are only cross-sectional, limiting the ability of researchers to control for unobservable characteristics that are fixed over time, such as developer ability. A survey that reached a more diverse set of software developers, that was longitudinal in structure, and that was designed with the basic economic theory of voluntary contributions in mind, would greatly help in empirically identifying the relative importance of the three key factors in the open source supply decision.

\subsection{Econometric Studies}

One of the most notable econometric studies to date that is related to the supply of open source software is Hann et al. (2004). The authors in this paper construct an original longitudinal dataset of 147 contributors to three different Apache projects. The study aims to measure the increase in developer wages due to the extent of contributions made to Apache projects, as well as the increase in wages due to achieving a higher rank within the Apache Software Foundation (ASF). If higher wages (skill prices) in the developer's regular employment are correlated with a higher volume of open source contributions, then this is interpreted as a human capital or learning effect. A higher volume of contributions proxies more open source programming ex- 
perience and greater knowledge. Any increase in skill prices deriving from a higher rank in ASF is interpreted by the authors as a signaling or sorting effect. ASF rank may be an effective means of conveying information about innate productivity levels that would otherwise be only imperfectly assessed in the market. ${ }^{9}$

With standard panel data wage regressions that control for unobserved individual fixed effects - such as developer ability - the authors find that there is little return to the volume of contributions, but achieving a higher rank in ASF significantly increases wages by $13-27 \%$, depending on the rank. The conclusion is that the signaling/sorting effect is much stronger than the human capital/learning effect in open source Apache projects.

Although Hann et al. (2004), exploit an original, longitudinal data set with detailed information on open source contributions, there are several limitations that cast doubt on the reliability of their results. As mentioned earlier in the context of existing developer surveys, the sample only includes open source developers. Individuals who choose not to participate in open source projects convey information about the experience and signaling value of open source participation yet they are not accounted for in estimation. For example, the return to ASF rank may be upward biased if those who do not participate in Apache projects know that they would not experience wage increases with higher ASF ranks. Non-participants may not need to signal their productivity to the market for developers. Note that non-participants may be open source developers that choose to contribute to open source projects other than Apache as well as developers that do not contribute to any open source projects.

An additional problem that may bias the results is that ASF rank may reflect additional dimensions of open source experience beyond the number of lines of con-

\footnotetext{
${ }^{9}$ There are five ranks (levels of recognition) in ASF. They are: developer, committer, project management committee member, ASF member, and ASF board member. Promotion to a higher rank is awarded upon positive peer review.
} 
tributed code. Therefore, the coefficient on rank may be partially absorbing the returns to open source experience. It should not be strictly interpreted as a return to signaling/sorting. ${ }^{10}$ Note that if open source experience, measured as lines-of-code contributed, does not accurately measure true experience then there may also be a bias in the coefficient on experience due to measurement error. That is, attenuation bias is another possibility why low estimated returns to open source experience were obtained.

On the role of open source license type in open source development activity, Lerner and Tirole (2005b) examine the determinants of license choice using the SourceForge database which contains information on approximately 40,000 open source projects. Lerner and Tirole (2005b) use the SourceForge database to run probit regressions in which the dummy dependent variable denotes either all licenses in the project are highly restrictive (GPL), or in separate specifications, some licenses in the project are highly restrictive. The independent variables capture project characteristics and are grouped under the headings, development stage (e.g., pre-alpha, alpha), environment (e.g., X11, Windows), intended audience (e.g., end-users, developers), natural language (e.g., French, Spanish), operating system (e.g., POSIX, Microsoft) and topic (e.g., communications, security).

The probit results indicate that restrictive licenses are more prevalent amongst projects that are targeted to end-users (e.g., desktop tools and games) as opposed to other developers or system administrators. This is consistent with the hypothesis mentioned earlier, in the basic theory of voluntary contributions, that restrictive licenses can substitute for otherwise low non-pecuniary benefits. Applications of this type may not have a strong ego-gratification component so that placing the

\footnotetext{
${ }^{10}$ Indeed, median lines of code within ASF rank, which is used as an instrument for rank in 2SLS versions of the regressions, is strongly correlated with ASF rank in first stage regressions. Putting the likely endogeneity of the instrument aside, the first stage results suggest that rank is another proxy for open source experience.
} 
project under a restrictive license may be the only way to substantially increase utility and induce participation. Also consistent with the basic theory of voluntary contributions is the finding that restrictive licenses are significantly less prevalent among projects geared towards other software developers or projects designed for operating in commercial environments. These latter projects likely have a higher ego-gratification component and/or signaling value, and less of a need for a restrictive license.

Although the Lerner and Tirole (2005a) study yields interesting insights into the determinants of a project license, it is limited in that it remains at the level of establishing statistical correlations. Data limitations prevent accounting for unobserved project characteristics that could confound the relationship between observed project characteristics and license choice. This makes it doubtful that they have identified any causal effects. The study also does not address the more interesting question of how license choice affects open source participation at the individual contributor level.

This latter question of how license type affects open source supply decisions is directly addressed in a paper by Fershtman and Gandal (2007). Also using the SourceForge database, the authors construct a panel of 71 open source projects observed nine time times over an eighteen month period (once every two months). They run linear regressions of output per contributor (measured as lines of code submitted) on license type, controlling for other project characteristics and unobserved random project effects. The results show that protecting code under more restrictive licenses induces more output per contributor. The authors conclude that the significant effect of license type is consistent with an ideological and/or status/signaling motivation to open source participation as hypothesized in the basic theory of voluntary contributions (see also Bonaccorsi and Rossi (2002)). 


\section{The Model}

The review of the empirical literature in the previous section highlights how prior econometric work has focussed on the influence of monetary rewards and type of open source license in isolation. In addition, there are no econometric studies that attempt to identify the role of non-pecuniary benefits. In this section, we propose an econometric framework that can be used to identify the relative importance of non-pecuniary benefits, monetary rewards and open source license type in a single model of forward-looking optimal decision-making.

Consider a software developer that chooses among three employment states and three open source project participation states at the start of each period $t$. Assume the decision problem begins at $t=\tau$ (age 18) and the terminal period, $t=T$, is the year before retirement (age 64). The length of each time period is a year. The three states in the employment choice set, denoted as $K$, are unemployment $(k=0)$, post-secondary schooling $(k=1)$ and full-time employment as a software developer $(k=2)$. The employment choice variable, $d_{i k t}^{e}$, is defined such that $d_{i k t}^{e}=1$ if developer $i$ chooses employment state $k$ at time $t$ and $d_{i k t}^{e}=0$ otherwise.

The three open source project participation states, denoted as $L$, are specified as no open source project participation $(l=0)$, participation in a project licensed under BSD or other licenses less restrictive than GPL $(l=1)$, and participation in a project in which all licenses are GPL $(l=2) .{ }^{11}$ The project participation choice variable, $d_{i l t}^{o s}$, is defined such that $d_{i l t}^{o s}=1$ if developer $i$ chooses open source participation state $l$ at time $t$ and $d_{i l t}^{o s}=0$ otherwise. Because the developer chooses both an employment state $k$ and a project participation state $l$ in each time period $t$, the dimension of the choice set in each period is $K * L$. However, the choice set is constrained by the receipt of job offers and open source project offers to be specified below.

\footnotetext{
${ }^{11} \mathrm{~A}$ non-negligible number of open source projects have multiple licenses attached to them (see Lerner and Tirole (2005)).
} 
The objective of the software developer is to choose an employment and project participation state in each time $t$ to maximize the expected present discounted value of remaining lifetime utility. Remaining lifetime utility at time $t$ for developer $i$ is

$$
V_{i t}\left(S_{i t}\right)=\max _{\left\{d_{i k t}^{e}, d_{i l t}^{o s}\right\}} E\left[\sum_{t=\tau}^{T} \delta^{\tau-t} U_{i t}(\cdot) \mid S_{i t}\right]
$$

where $V_{i t}$ is the value function, $U_{i t}(\cdot)$ is the utility flow, $\delta$ is the subjective discount factor and $S_{i t}$ is the state space. $S_{i t}$ consists of all the factors known to the individual at time $t$ affecting current returns or the probability distribution of future returns.

The maximization problem in (1) can be recast in terms of alternative specific value functions, $V_{i t}^{k l}\left(S_{i t}\right)$, each of which follow Bellman's equation, i.e.,

$$
\begin{aligned}
V_{i t}\left(S_{i t}\right) & =\max _{\{k \in K, l \in L\}}\left[V_{i t}^{k l}\left(S_{i t}\right)\right] \text { where } \\
V_{i t}^{k l}\left(S_{i t}\right) & =U_{i t}(\cdot)+\delta E\left(V_{i, t+1}\left(S_{i, t+1}\right) \mid d_{i k t}^{e}, d_{i l t}^{o s}, S_{i t}\right), t<T \\
& =U_{i T}(\cdot)
\end{aligned}
$$

In the terminal period $T$, there is no future component to the value function and the individual maximizes current utility flow $U_{i T}$.

For simplicity, $U_{i t}$ in (2) is assumed to be a linear function of consumption and open source participation status, i.e.,

$$
U_{i t}(\cdot)=C_{i t}+\left(\gamma_{1}+v_{i 1 t}\right) d_{i 1 t}^{o s}+\left(\gamma_{2}+v_{i 2 t}\right) d_{i 2 t}^{o s}
$$

where $C_{i t}$ is current period consumption, $\gamma_{1}$ is the non-pecuniary return to participating in an open source project not licensed solely under GPL, and $\gamma_{2}$ is the non-pecuniary benefit of participating in an open source project that is licensed only under GPL. $\gamma_{1}$ and $\gamma_{2}$ capture utility increases deriving from ego-gratification and ideological satisfaction that interact with license type. $v_{i 1 t}$ and $v_{i 2 t}$ in (3) are stochastic error terms that capture heterogeneity in the appeal of open source projects within each licensing category. 
Participation in open source projects is assumed to be constrained by the arrival of open source project "offers". In each period $t$, it is assumed that there is a nonzero probability, denoted by $\lambda_{1 t}^{o s}$, that a developer receives an offer to participate in a project not licensed solely under GPL. With probability $\lambda_{2 t}^{o s}$, a developer receives an offer to participate in a project that is licensed solely under GPL, and with probability $1-\lambda_{1 t}^{o s}-\lambda_{2 t}^{o s}$, the developer receives no offer and cannot choose to participate in an open source project for that period. The open source project arrival rates reflect prior licensing decisions by project initiators and are taken as given by the individual developer. The arrival rates could be further specified as functions of individual characteristics and current employment state in order to capture differential search intensity for projects on the part of developers. It is assumed that only one open source project offer, if any, arrives in each period $t$.

Consumption in each period $t$ is determined by a budget constraint that is assumed to be satisfied in each period and which takes the following form,

$$
C_{i t}=b_{0} d_{i 0 t}^{e}+\left[b_{1}+\varepsilon_{i 1 t}\right] d_{i 1 t}^{e}+w_{i t} d_{i 2 t}^{e}-c\left(d_{i 1 t}^{o s}+d_{i 2 t}^{o s}\right)
$$

$b_{0}$ is the current period return to being in the unemployment state and is meant to capture unemployment insurance, welfare benefits, liquidation of previous assets, and the net consumption value of leisure. $b_{1}$ is the deterministic component of the current period return to being a post-secondary school student. $b_{1}$ reflects in-school labor market earnings and the net consumption value of schooling less tuition costs and other related expenses. $\varepsilon_{i 1 t}$ is the stochastic component of schooling's current period return which captures variability in in-school labor market earnings and other shocks to preferences for schooling. $w_{i t}$ is the wage the individual receives as a full-time software developer and is also allowed to be stochastic. ${ }^{12}$ The parameter $c$ is the

\footnotetext{
${ }^{12} \mathrm{~A}$ non-zero choice probability for each of the three employment states can be generated with only two error terms. Therefore, it is not strictly necessary to specify the returns to unemployment to be stochastic.
} 
consumption cost of open source project participation which is restricted to be the same regardless of open source license type. The cost of project participation includes lost leisure time as well as the costs of submission/distribution of open source code.

The wage $w_{i t}$ in (4) is further specified to be a function of education, experience, age, and an unobserved individual effect. That is, $w_{i t}=w_{i t}\left(x_{i 1 t}, x_{i 2 t}, o s_{i t}, t, \alpha_{i}, \varepsilon_{i 2 t}\right)$ where $x_{i 1 t}$ is accumulated years of post-secondary education, $x_{i 2 t}$ is accumulated general experience as a software developer, and $o s_{i t}$ is accumulated specific experience as an open source software developer. The influence of age is captured by $t, \alpha_{i}$ is an unobserved individual fixed effect, and $\varepsilon_{i 2 t}$ is a productivity shock assumed to be i.i.d. and serially uncorrelated. The wage function can also be augmented with observed individual characteristics such as race and gender. However, it is generally difficult to estimate dynamic programming models of labor force dynamics with $\varepsilon_{i 2 t}$ allowed to be serially correlated.

The education and experience terms in $w_{i t}$ evolve according to the laws of motion,

$$
\begin{aligned}
x_{i 1, t+1} & =x_{i 1 t}+d_{i 1 t}^{e} \\
x_{i 2, t+1} & =x_{i 2 t}+d_{i 2 t}^{e} \\
o s_{i, t+1} & =o s_{i t}+d_{i 1 t}^{o s}+d_{i 2 t}^{o s}
\end{aligned}
$$

with initial conditions $x_{i 1 \tau}=x_{i 2 \tau}=o s_{i \tau}=0$. Accumulated open source experience is augmented by one year regardless of open source project license type. However, if empirically important, it would be easy to allow for two different accumulated open source experience variables.

In order to minimize the number of distributional assumptions in the model, the unobserved individual effect, $\alpha_{i}$ is specified to be stochastic with a nonparametric mass point distribution. That is, $\alpha_{i}$ is assumed to be a linear function of two unobserved "type" dummies,

$$
\alpha_{i}=\theta_{1} A_{1 i}+\theta_{2} A_{2 i}
$$

where $A_{1 i}$ is a dummy variable for unobserved type 1 and $A_{2 i}$ is a dummy variable for 
unobserved type 2. $A_{0 i}$ is a dummy for unobserved "type" 0 . As the base type, $A_{0 i}$ is excluded from (5). In this setup, three type probabilities, which define the discrete nonparametric distribution of $\alpha_{i}$, are estimated along with the two non-zero location points of $\alpha_{i}$, denoted by $\theta_{1}$ and $\theta_{2}$.

Assuming a standard Mincerian wage function, $w_{i t}$ can be written as,

$$
w_{i t}=\exp \left(\beta_{0 k}+\beta_{1} x_{i 1 t}+\beta_{2} x_{i 2 t}-\beta_{3} x_{i 2 t}^{2}+\beta_{4} o s_{i t}+\beta_{5} t+\theta_{1} A_{1 i}+\theta_{2} A_{2 i}+\varepsilon_{i 2 t}\right) .
$$

An additional constraint imposed on the maximization problem is that a developer must receive a job offer prior to receiving a wage offer determined by (7). That is, with probability $\lambda_{t}^{e}$ the developer receives a wage offer of $w_{i t}$, and with probability $1-\lambda_{t}^{e}$ there is no wage offer forthcoming in period $t$. In order to incorporate the possibility that open source experience could have a signaling payoff as well as a direct productivity return (as in Hann et. al. (2004)), $\lambda_{t}^{e}$ could be specified as a function of accumulated open source experience at time $t$, as well as individual characteristics and previous employment state.

It is important to note that the model in equations (1)-(7) explicitly recognizes that education, employment and open source participation choices are jointly determined as well as forward-looking. Moreover, the model makes it clear which parameters are associated with current non-pecuniary benefits to open source participation, and which parameters are associated with future monetary rewards. In addition, the influence of open source license type in the decision to participate in an open source project is made explicit. The relative importance of non-pecuniary benefits, future monetary rewards and open source license type can be empirically assessed in this model using the standard techniques of dynamic programming solution and structural estimation (see e.g., Keane and Wolpin (1994), Keane and Wolpin (1997) and Sauer (1998)). 


\section{Conclusion}

A review of the basic theory of optimal open-source software contributions points to three key factors affecting the decision to contribute to the open-source development process. These three factors are non-pecuniary benefits, future expected monetary returns, and open-source licence type. Unfortunately, the developer surveys that are available to researchers today are inadequate for studying the relative importance of these three key factors. Econometric studies that have collected original datasets are also limited because they generally consider the role of monetary rewards and licence type in isolation, and do not attempt to measure the influence of non-pecuniary benefits.

In order to fill the gap in the literature, this paper proposes a dynamic programming model of open-source participation decisions that could provide empirical estimates of the relative importance of non-pecuniary benefits, monetary rewards and licence type within a single model. The model allows for three employment states (non-employment, schooling, and employment as a software developer) and three open-source participation states (no participation, participation in a project not licensed under GPL, and participation in a project licensed under GPL). In the model, developers choose an employment state and a project participation state in each period but are constrained by the arrival of employment and project participation offers. As soon as suitable panel data become available, the model could be estimated using the standard techniques employed in the literature on the solution and estimation of dynamic programming models.

In sum, economists' understanding of the motivations and supply decisions of open source developers is still at an early stage. Higher quality data and more comprehensive empirical models of the type proposed in this paper are needed to advance our knowledge. A better understanding of the determinants of open source software supply is becoming increasingly important as businesses and governments more heavily rely on this "non-traditional" software to meet their computing needs. A firmer 
grasp of the relative importance of non-pecuniary benefits, expected future monetary rewards and open source license type would help predict future changes in open source software supply as well as help economists more accurately evaluate proposed changes in public policy that affect the software industry. 


\section{References}

[1] Berlecon Research (2002), "Firms' Open Source Activities: Motivations and Policy Implications," Floss Final Report. International Institute of Infonomics, University of Maastricht, The Netherlands.

[2] Bonaccorsi, A., and Rossi, C. (2003), "Why Open Source can Succeed," Research Policy, 32, 1243-1258.

[3] Boston Consulting Group (2003), Boston Consulting Group/OSDN Hacker Survey, Boston: Boston Consulting Group.

[4] Fershtman C., and N. Gandal (2007), "Open Source Motivation and Restrictive Licensing," International Economics and Economic Policy, 4, 209-225

[5] Ghosh R., R. Glott, B. Kriger, and G. Robles (2002), Free/Libre and Open Source Software: Survey and Study, University of Maastricht Institute of Infonomics and Berlecon Research GmbH, mimeo.

[6] Hann I., J. Roberts, S. Slaughter, and R. Fielding (2004), "An Empirical Analysis of the Economic Returns to Open Source Participation," Unpublished working paper, Carnegie Mellon University.

[7] Harhoff D., J. Henkel, and E. von Hippel (2003), "Profiting from Voluntary Information Spillovers: How Users Benefit by Freely Revealing Their Innovations," Research Policy, 32, 1753.

[8] Haruvy E., F. Wu, and S. Chakravarty (2003), "Incentives for Developers' Contributions and Product Performance Metrics in Open Source Development: An Empirical Investigation," unpublished working paper, University of Texas at Dallas.

[9] Hayek F.A. (1945), "The Use of Knowledge in Society," American Economic Review, 35, 4, 519-530. 
[10] von Hippel E. (2002), "Open Source Projects as Horizontal Innovation Networks - By and For Users," MIT Sloan School of Management Working Paper No. 4366-02.

[11] Henkel, J. (2005), "The Jukebox Mode of Innovation - A Model of Commercial Open Source Development," Technische Universitat Munich, mimeo.

[12] Hertel, G., Niedner, S. \& Herrmann, S. (2003). Motivation of software developers in open source projects: An internet-based survey of contributors to the Linux kernel. Research Policy, 32, 1159-1177.

[13] Johnson, J.P. (2002), "Open Source Software: Private Provision of a Public Good," Journal of Economics and Management Strategy, 11(4), Winter, 637662.

[14] Keane, M.P., and K.I. Wolpin, (1994), "The Solution and Estimation of Discrete Choice Dynamic Programming Models by Simulation and Interpolation: Monte Carlo Evidence," Review of Economics and Statistics, 76, 648-672.

[15] Keane, M.P., and K.I. Wolpin, (1997), "The Career Decisions of Young Men," Journal of Political Economy, 105, 473-522.

[16] Lakhani K. and E. von Hippel (2003), "How Open Source Software Works: 'Free' User-to-User Assistance," Research Policy, 32, 923-943.

[17] Lakhani K. and R. Wolf (2005), "Why Hackers Do What They Do: Understanding Motivation and Effort in Free/Open Source Software Projects," in J. Feller, B. Fitzgerald, S. Hissam, and K. Lakhani (eds.) Perspectives in Free and Open Source Software, MIT: Cambridge and London.

[18] Lerner J. and J. Tirole (2002), "Some Simple Economics of Open Source," Journal of Industrial Economics, 52, 197-234. 
[19] Lerner J. and J. Tirole (2005a), "The Economics of Technology Sharing: Open Source and Beyond," Journal of Economic Perspectives, forthcoming.

[20] Lerner J. and J. Tirole (2005b): "The Scope of Open Source Licensing," Journal of Law, Economics, and Organization, 21, 20-56

[21] MacCormack, A. (2003), "Evaluating Total Cost of Ownership for Software Platforms: Comparing Apples, Oranges and Cucumbers," AEI-Brookings Joint Center for Regulatory Studies, mimeo.

[22] Maurer, S.M., and S. Scotchmer (2005), "Open Source Software: The New Intellectual Property Paradigm," NBER Working Paper 12148.

[23] Raymond E. (1999a), "The Cathedral and the Bazaar," The Cathedral and the Bazaar: Musings on Linux and Open Source by an Accidental Revolutionary, Cambridge: O'Reilly, 19-64.

[24] Raymond E. (1999b), "Homesteading the Noosphere," The Cathedral and the Bazaar: Musings on Linux and Open Source by an Accidental Revolutionary, Cambridge: O'Reilly, 65-112.

[25] Raymond E. (1999c), "The Magic Cauldron," The Cathedral and the Bazaar: Musings on Linux and Open Source by an Accidental Revolutionary, Cambridge: O'Reilly, 113-143.

[26] Sauer, R.M. (1998), "Job Mobility and the Market for Lawyers," Journal of Political Economy, 106, 147-171.

[27] West J. and S. Gallagher (2004), "Key Challenges of Open Innovation: Lessons from Open Source Software," San Jose State College of Business, mimeo.

[28] Wheeler, D. (2004), "Why Open Source Software/Free Software (OSS/FS)? Look at the Numbers!" http:///www.dwheeler.com/oss_fss_why.html (accessed December 12, 2004). 
Table 1

Descriptive Statistics

FLOSS-EU

$(\mathrm{N}=2718)$

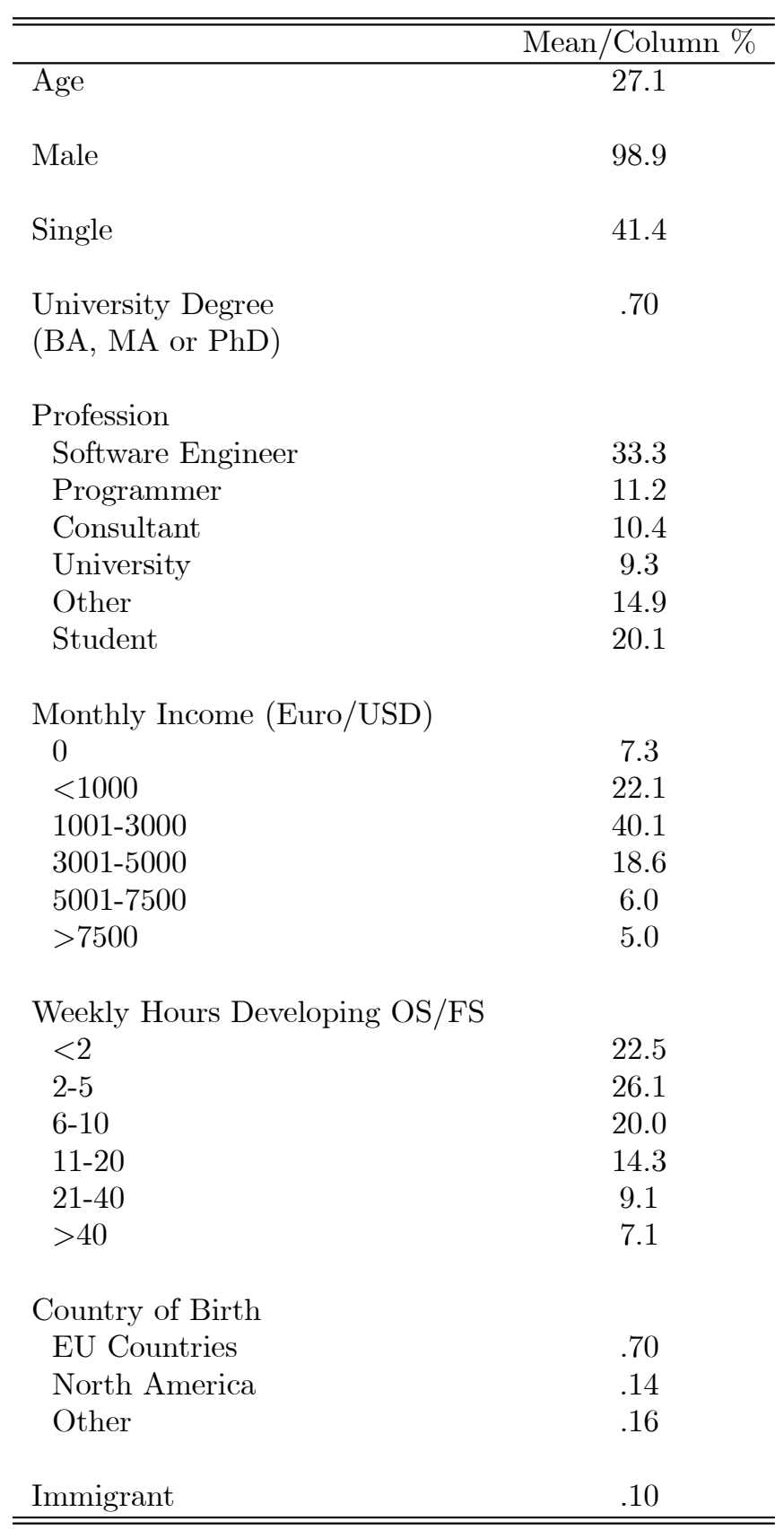

Source: Gosh et. al. (2002) 
Table 2

Developer Motivations

FLOSS-EU

$(\mathrm{N}=2718)$

\begin{tabular}{lc}
\hline \hline & Percentage \\
\hline Reason Joined OS/FS Community? & 78.9 \\
learn and develop new skills & 49.8 \\
share knowledge and skills & 34.5 \\
participate in a new form of cooperation & 33.7 \\
improve OS/FS products of other developers & 30.6 \\
participate in OS/FS scene & 30.1 \\
software should be free & 29.7 \\
solve problem couldn't with proprietary software & 23.9 \\
improve job opportunities & 23.8 \\
get help in realizing idea for a software product & 19.0 \\
limit power of large software companies & 9.1 \\
get a reputation in OS/FS community & 8.9 \\
distribute not marketable software product & 4.4 \\
make money & 1.9 \\
don't know & \\
Receive Monetary and Non-Monetary Rewards from OS/FS? & \\
& \\
no, do not earn money from OS/FS & 46.3 \\
yes, directly; paid for administering OS/FS & 18.4 \\
yes, indirectly; got job because of OS/FS experience & 17.5 \\
yes, directly; paid for developing OS/FS & 15.7 \\
yes, indirectly; but also develop OS/FS at work & 12.8 \\
yes, directly; paid for supporting OS/FS & 11.9 \\
yes, indirectly; other reasons & 7.8 \\
yes, indirectly; job discription doesn't include OS/FS Work & 5.2 \\
yes, directly; other reasons & 4.4 \\
\hline \hline
\end{tabular}

Source: Gosh et. al. (2002) 